\title{
Bedside and continuous assessment of arterial load in critically-ill patients by combined analysis of esophageal doppler blood flow and arterial pressure waveform: preliminary results
}

Ml Monge García 1*, A Santos Oviedo 2,3,4, P Guijo González', M Gracia Romero', A Gil Cano

From ESICM LIVES 2015

Berlin, Germany. 3-7 October 2015

\section{Introduction}

Because the oscillatory nature of the arterial pressure and blood flow, the input impedance assessed in frequency domain provides the best description of the arterial load [1]. However, this approach is complex and not feasible in clinical practice. Nowadays, it is possible to measure simultaneously flow and pressure at the bedside using minimally invasive monitoring.

\section{Objectives}

To test the usefulness of continuous assessment of arterial load based on a 3-element Windkessel model by a combined analysis of the esophageal Doppler derived-blood flow and arterial pressure waveform, against standard frequency-domain analysis of arterial impedance.

\section{Methods}

Time-domain variables of arterial impedance were obtained by the simultaneous analysis of the Doppler derived-blood flow and arterial pressure. A 3-element Windkessel model was used, consisting on arterial resistance $(\mathrm{R}=$ mean arterial pressure/cardiac output), arterial compliance $[\mathrm{C}=$ stroke volume $(\mathrm{SV}) /$ arterial pulse pressure), characteristic impedance $\left[\mathrm{Zc}_{\mathrm{t}}=\right.$ maximum derivative of pressure $\left(\mathrm{dP}_{\max } / \mathrm{dt}\right) /$ maximum derivative of aortic blood flow $\left.\left(\mathrm{dQ}_{\max } / \mathrm{dt}\right)\right]$ (Figure 1). Effective arterial elastance $(\mathrm{Ea}=90 \%$ of systolic arterial pressure/SV) was used as a lumped parameter of the whole arterial load. Frequencydomain analysis of the pressure-blood flow waveforms was obtained to estimate the input impedance $\left(Z_{\text {in }}\right)$, characteristic impedance (Zc, average of the modulus of $4^{\text {th }}$

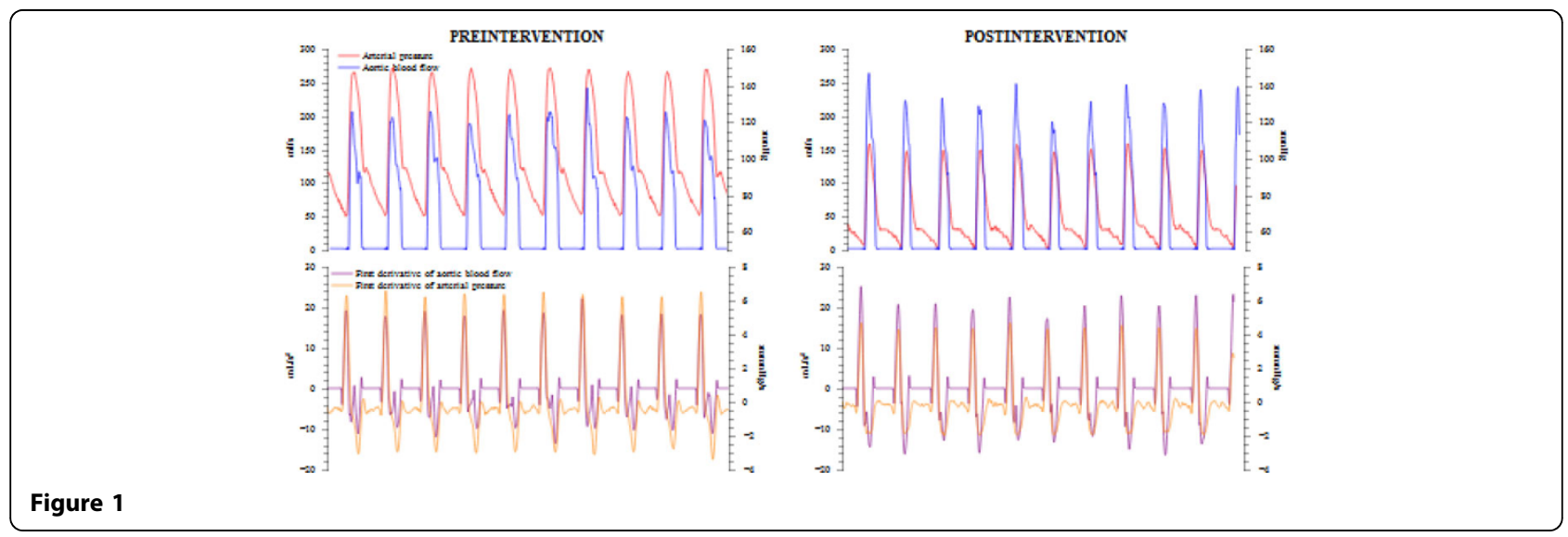

${ }^{1}$ Hospital SAS de Jerez de la Frontera, Unidad de Cuidados Intensivos, Jerez de la Frontera, Spain

(c) 2015 Monge García et al.; This is an Open Access article distributed under the terms of the Creative Commons Attribution License (http://creativecommons.org/licenses/by/4.0), which permits unrestricted use, distribution, and reproduction in any medium, provided the original work is properly cited. 


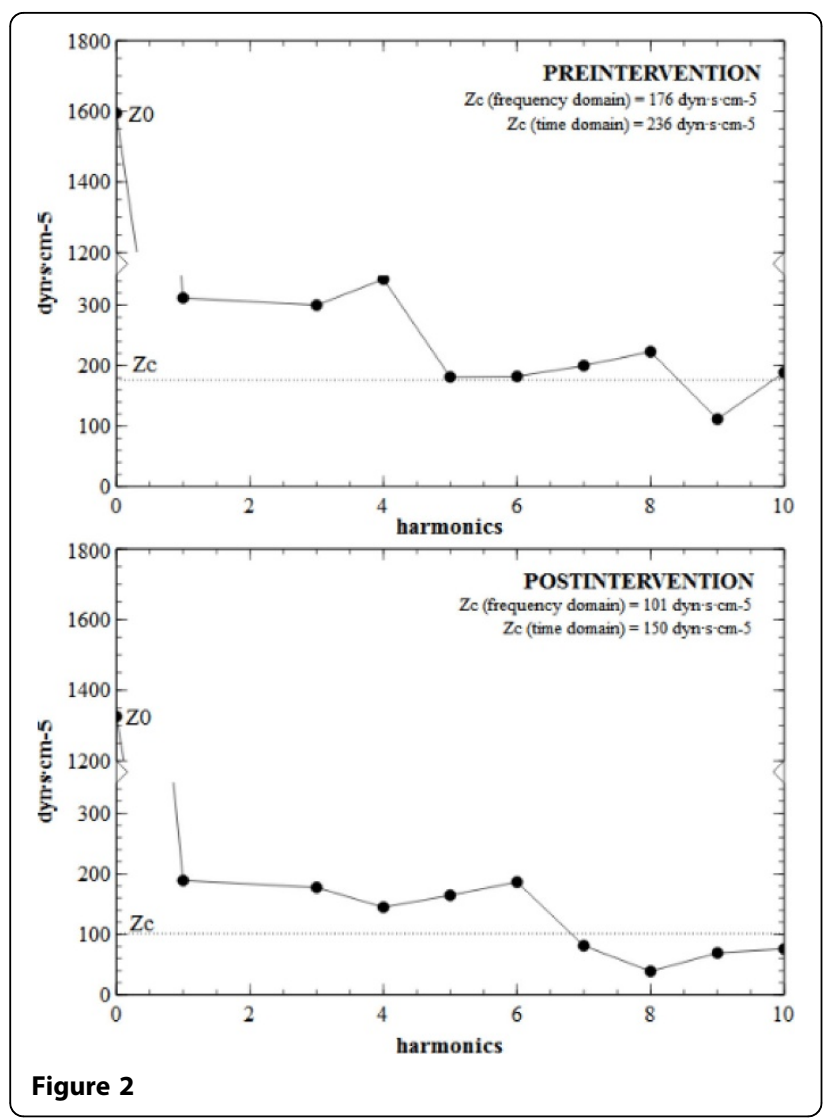

and $10^{\text {th }}$ harmonics, Figure 2), and $\mathrm{Z}_{1}$ (modulus at the first harmonic, as an index of compliance). Reflection coefficient $(\mathrm{RC})$ in time and frequency domain was estimated as $(\mathrm{SVR}-\mathrm{Zc}) /(\mathrm{SVR}+\mathrm{Zc})$. Measurements were obtained in patients in whom a vasodilators or vasoconstrictor was introduced or dosage was changed, and a significant variation in arterial load was expected.

\section{Results}

Ten measurements in 6 patients were obtained. Time and frequency-domain derived $\mathrm{Zc}$ were similar at pre (222 vs 203 dyn $\bullet s \cdot \mathrm{cm}^{-5}$; P = n.s.) and post-intervention (205 vs 165 dyn $\bullet \cdot \bullet \mathrm{cm}^{-5}$; P = n.s.). Pre and post-intervention values and percentage changes of $Z_{c}$ and $Z_{c_{t}}$ were strongly correlated $\left(\mathrm{R}^{2}=0.94, \mathrm{R}^{2}=0.95 ; \mathrm{R}^{2}=0.96\right.$; $\mathrm{P}<0.0001)$. Time and frequency-domain derived reflection coefficient were also correlated at pre $\left(R^{2}=0.93\right.$; $\mathrm{P}<0.0001)$, post-intervention $\left(\mathrm{R}^{2}=0.85 ; \mathrm{P}<0.0001\right)$ and percentage changes $\left(R^{2}=0.85 ; P<0.0001\right)$. Changes in net arterial compliance and $\mathrm{Z}_{1}$ were also inversely correlated $\left(\mathrm{R}^{2}=0.59 ; \mathrm{P}<0.0001\right)$. As expected, $\mathrm{Z}_{0}$ and $\mathrm{R}$ showed an equivalent behavior.

\section{Conclusions}

Our preliminary results shows that continuous and noninvasive assessment of different aspects of arterial load by combined analysis of Doppler derived-aortic blood flow and arterial pressure could be feasible at the bedside and comparable to standard frequency domain analysis.

\section{Authors' details}

${ }^{1}$ Hospital SAS de Jerez de la Frontera, Unidad de Cuidados Intensivos, Jerez de la Frontera, Spain. ${ }^{2}$ Massachusetts General Hospital, Department of Anesthesia, Boston, MA, USA. ${ }^{3}$ Uppsala University, Surgical Sciences Department, Uppsala, Sweden. ${ }^{4}$ M+Vision Cofund, Madrid, Spain.

Published: 1 October 2015

\section{Reference}

1. Nichols WW, O'Rourke M: McDonald's Blood Flow in Arteries: Theoretical, Experimental and Clinical principles. London: Oxford University Press; Edited by Nichols WW, O'Rourke M , 5 edn 2005:233-267.

doi:10.1186/2197-425X-3-S1-A593

Cite this article as: Monge García et al:: Bedside and continuous assessment of arterial load in critically-ill patients by combined analysis of esophageal doppler blood flow and arterial pressure waveform: preliminary results. Intensive Care Medicine Experimental 2015 3(Suppl 1):A593.

\section{Submit your manuscript to a SpringerOpen ${ }^{\odot}$ journal and benefit from:}

- Convenient online submission

- Rigorous peer review

- Immediate publication on acceptance

- Open access: articles freely available online

- High visibility within the field

- Retaining the copyright to your article

Submit your next manuscript at $>$ springeropen.com 